\title{
Correction to: miR-762 modulates thyroxine-induced cardiomyocyte hypertrophy by inhibiting Beclin-1
}

\author{
Zheng Qiang $\cdot$ Beifang Jin $\cdot$ Yuntao Peng $\cdot$ Yan Zhang $\cdot$ Junfeng Wang $\cdot$ Chen Chen $\cdot$ Xinfeng Wang $\cdot$ Fang Liu
}

Published online: 14 January 2020

(c) Springer Science+Business Media, LLC, part of Springer Nature 2020

\section{Correction to: Endocrine}

https://doi.org/10.1007/s12020-019-02048-y

The original version of this article unfortunately contained the below mistakes. This has been corrected with this erratum.

1. Table. 2 Sequences for primers

The sequences of $\beta$-MHC: Forward and Reverse, miR-762 mimic, and miR-762 inhibitor are incorrect. Below are the correct sequences.

$\beta$-MHC: Forward 5-TGCAGACATAGAGACCTACCTT C-3

Table 1 Sequences for primers

\begin{tabular}{|c|c|}
\hline Gene & q-PCR \\
\hline miR-762 & $\begin{array}{l}\text { Forward 5-ATATATAGGGGCTGGGGCCG-3 } \\
\text { Reverse 5-CAGTGCGTGTCGTGGAGT-3 }\end{array}$ \\
\hline U6 & $\begin{array}{l}\text { Forward 5-CTCGCTTCGGCAGCACA-3 } \\
\text { Reverse 5-AACGCTTCACGAATTTGCGT-3 }\end{array}$ \\
\hline ANP & $\begin{array}{l}\text { Forward 5-ACGCAGCTTGGTCACATTGC-3 } \\
\text { Reverse 5-CCACTAGACCACTCATCTAC-3 }\end{array}$ \\
\hline$\beta-\mathrm{MHC}$ & $\begin{array}{l}\text { Forward 5-TGCAGACATAGAGACCTACCTTC-3 } \\
\text { Reverse 5-CAGCATGTCTAGAAGCTCAGG-3 }\end{array}$ \\
\hline Beclin-1 & $\begin{array}{l}\text { Forward 5-CGTACAGGATGGACGTGGAG-3 } \\
\text { Reverse 5-GGCAAGACCCCACTTGAGAT-3 }\end{array}$ \\
\hline GAPDH & $\begin{array}{l}\text { Forward 5-AGGTCGGTGTGAACGGATTTG-3 } \\
\text { Reverse 5-TGTAGACCATGTAGTTGAGGTCA-3 }\end{array}$ \\
\hline miR-762 mimic & 5-GGGGCUGGGGCCGGGACAGAGC-3 \\
\hline $\begin{array}{l}\operatorname{miR}-762 \\
\operatorname{mimic} \mathrm{NC}\end{array}$ & 5-UCACAACCUCCUAGAAAGAGUAGA-3 \\
\hline $\begin{array}{l}\text { miR-762 } \\
\text { inhibitor }\end{array}$ & 5-GCUCUGUCCCGGCCCCAGCCCC-3 \\
\hline $\begin{array}{l}\text { miR-762 } \\
\text { inhibitor NC }\end{array}$ & 5-CAGUACUUUUGUGUAGUACAAA-3 \\
\hline
\end{tabular}

Reverse 5-CAGCATGTCTAGAAGCTCAGG-3 miR-762 mimic: 5-GGGGCUGGGGCCGGGACAGAGC-3 miR-762 inhibitor: 5-GCUCUGUCCCGGCCCCAGCCC C-3

\section{Figure 1}

2 panels were marked as "f' in Fig. 1. The last "f' panel in the bottom should be "j".

\section{Figure 3.}

The panel "l" in Fig. 3, the labels of "3" and "5" were inversed, and "WU-Beclin-1-3'UTR" should be "MUBeclin-1-3'UTR". Below is the correction. 
Fig. 1 Intraperitoneal injection of thyroxine successfully induces cardiomyocyte hypertrophy. a Serum TT3

after intraperitoneal injection of normal saline or T4 solution. $\mathbf{b}$ Serum TT4 after intraperitoneal injection of normal saline and T4 solution. c Weight changes from week 9 to week 16. d Heart beats per minute. e Heart perfusion after draining of blood. f Heart weight after draining of blood. $\mathbf{g}$ Vernier caliper measures the longest vertical diameter of the heart. $\mathbf{h}$ Vernier caliper measures the widest transverse diameter of the heart. $\mathbf{i}$ The ratio of heart weight to body weight. $\mathbf{j}$ The ratio of heart weight to tibia length. (** $P<0.01$ vs the control group; $n \geq 9$ independent samples for each group)
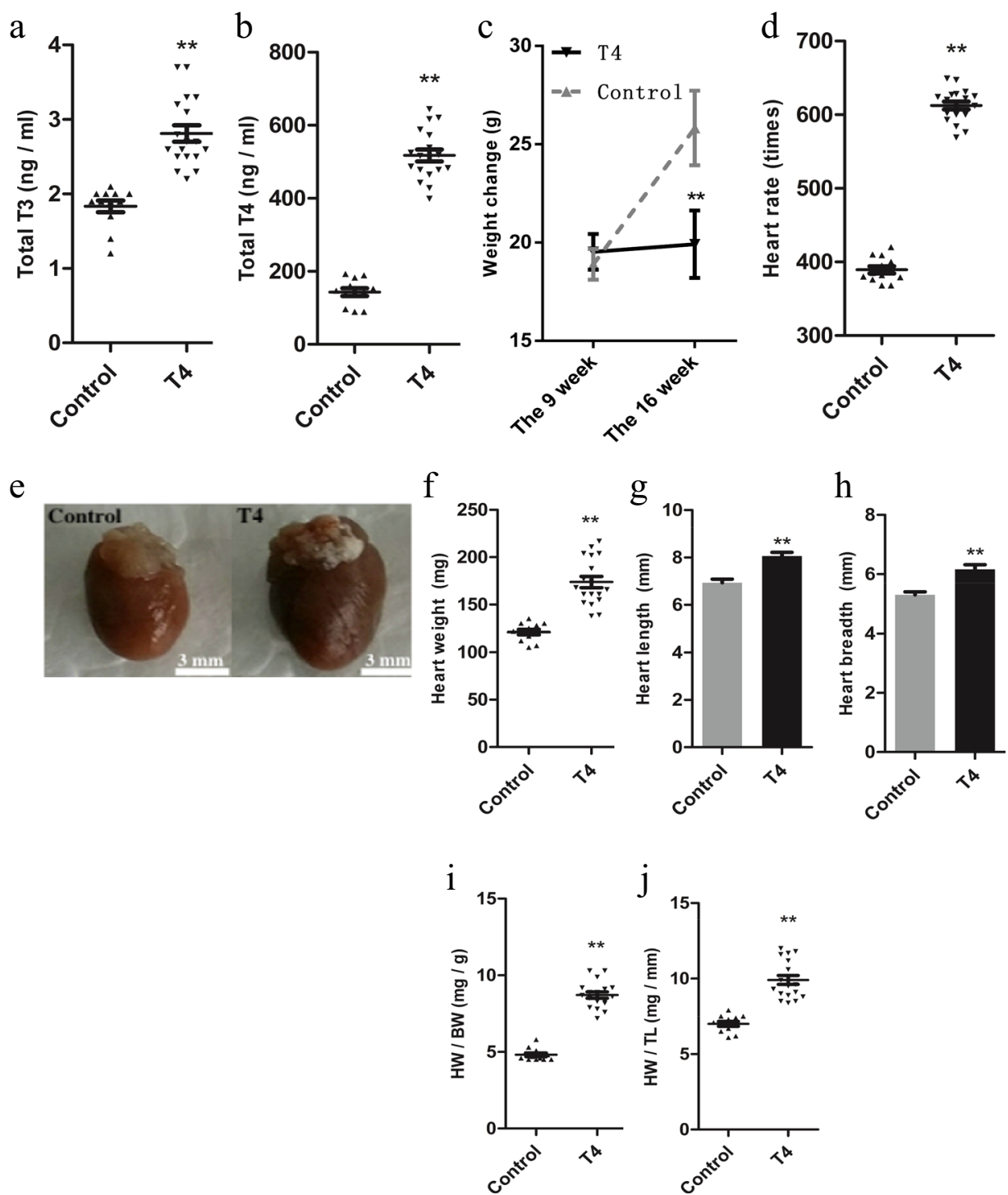
Fig. 3 Autophagy plays a key role in thyroxine-induced cardiomyocyte hypertrophy. a. Expression of LC3 and Beclin-1 protein in the heart. $\mathbf{b}$.

Transmission electron microscopy of the heart. Autophagic vacuoles are green, and autolysosomes are red, $10000 x$. c. Immunofluorescence staining of the heart, LAMP2 protein is red, LC3 protein is green, cell nuclei are blue, and autolysosomes are yellow, 200x. d. Semiquantitative analysis of miR-762 gene expression in the heart. e. Semiquantitative analysis of Beclin-1gene expression in the heart. $\mathbf{f}$. Semiquantitative analysis of LC3 protein in the heart. $\mathbf{g}$. Semiquantitative analysis of Beclin-1 protein in the heart. $\mathbf{h}$. Semiquantitative analysis of autophagic vacuoles with transmission electron microscopy. i. Semiquantitative analysis of LAMP2 protein with immunofluorescence staining. $\mathbf{j}$. Semiquantitative analysis of LC3 protein with immunofluorescence staining. $\mathbf{k}$. Semiquantitative analysis of autolysosomes with immunofluorescence staining. $\mathbf{l}$. The sequence of the Beclin-1 3'UTR (http://www.Ensembl.org/) and binding site between miR762 and Beclin-1 in mice (http://www.Targetscan.org/). m. Semiquantitative analysis of luciferase activity in 293A cells. $(* * P<0.01$ vs the control group; $\mathrm{n} \geq 9$ independent samples for each group) a
Control

T4

Beclin-1

LC3 I

LC3 II

GAPDH

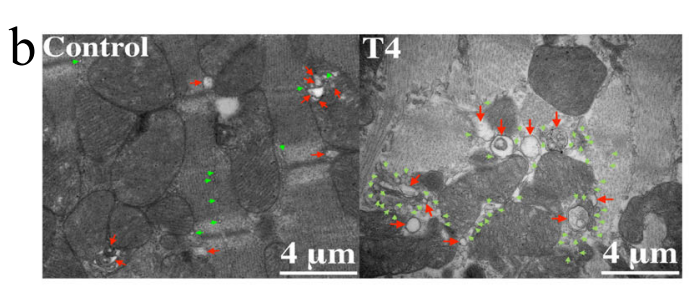

C LAMP2

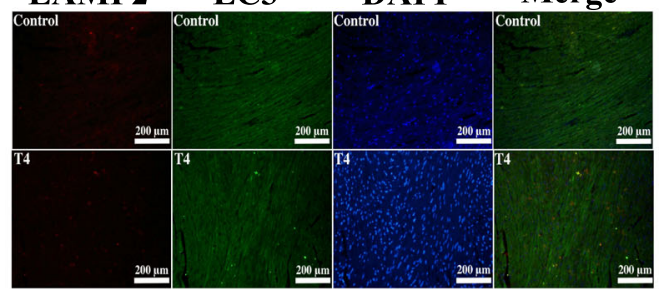

1 w

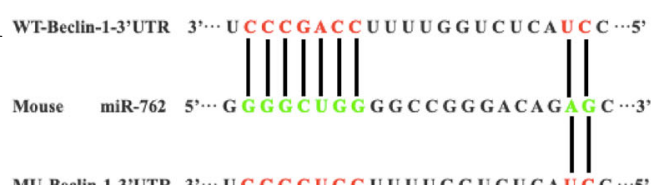

d

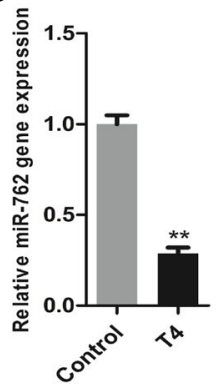

f

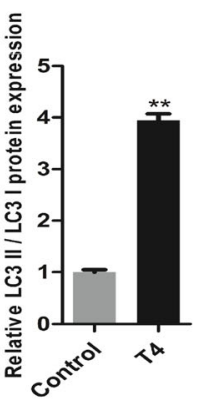

$\mathrm{h}$

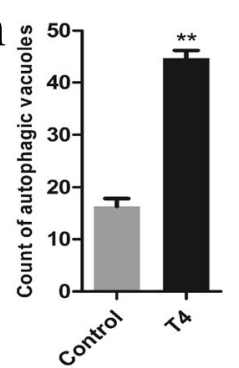

e

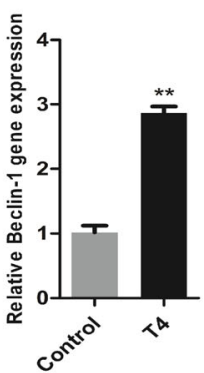

$\mathrm{g}$
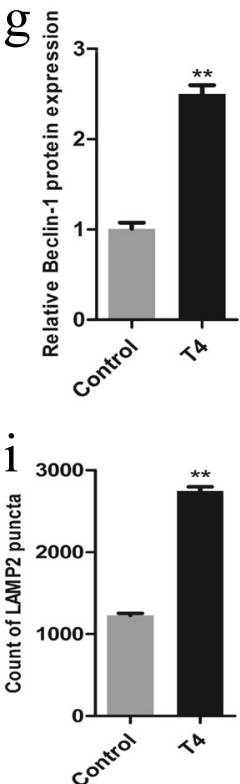

$\mathrm{m}$

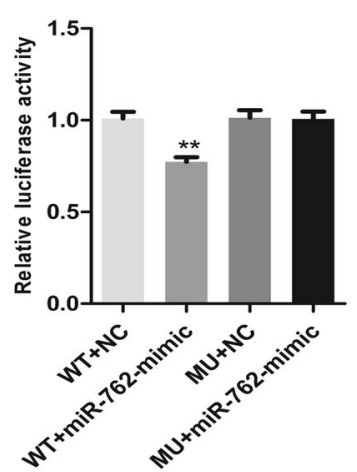

